\title{
Automatic Monitoring and Controlled Atmosphere System Using Arduino on Tropical Fruit Container Integrated with IoT
}

\author{
Alam Baheramsyah ${ }^{1}$, Khitoh Fatahilah ${ }^{2}$ \\ (Received: 08 March 2021 / Revised: 23 June 2021 / Accepted: 24 June 2021)
}

\begin{abstract}
Indonesia is a tropical country that is gifted with various kinds of abundant natural resources. Among them are exotic fruits which are in great demand by other people in the world. Meanwhile, in the delivery and storage process for distribution, technology that can maintain the resilience of the fruit is needed so that it does not ripen quickly, thereby increasing its economic value. From this problem, a device called Controlled Atmosphere Storage (CAS) was created which could store fruit and adjust its room conditions according to the specific air requirements of each commodity in the container. The control system design in this study aims to determine how to regulate the levels of ethylene, oxygen, carbon dioxide, and temperature by using the Arduino Uno as a microcontroller and integrating it with the IoT system. The system consists of a microcontroller, DHT22 sensor, MQ 135 sensor, MQ5 sensor, KE25 sensor, relay, Esp8266, and actuators such as fans and servo. From the experimental results, it is known that the control system used is capable of conducting air conditioning in the container and can integrate it with the IoT concept using Thingspeak.com media.
\end{abstract}

Keywords-CAS, IoT, microcontroller, thingspeak.

\section{INTRODUCTION}

$\mathrm{S}$ torage that is using the way of adjusting the composition of the air or regulation of oxygen concentration and carbon dioxide is known as atmospheric controlled storage. Controlled atmosphere engineering on storage has the aim of controlling the metabolism of the product to keep it fresh so that the shelf life can be extended. The temperature, oxygen, ethylene, and carbon dioxide concentrations around the product are kept within a certain parameter or concentration which is desired. This study aims to design an oxygen control and monitoring system for carbon dioxide as well as temperature, humidity, and ethylene levels in the storage room by implementing an Arduino Uno microcontroller. Many investigations have shown that the basic advantages of fruit preservation in a controlled atmosphere are as follows:

A) The so-called low-temperature diseases are prevented during refrigeration.

B) Infestation of fruits by other physiological diseases frequently encountered when fruits are preserved in refrigerators in conventional fruit storages is reduced.

C) The taste and fruit aroma are better preserved.

D) The consistency of fruits is maintained for longer periods. The fruit losses in the controlled atmosphere are reduced by half to one-third, while the period of preservation is significantly

Alam Baheramsyah is with Department of Marine Engineering, Institut Teknologi Sepuluh Nopember, Surabaya, 60111, Indonesia. Email: abaheramsyah@gmail.com

Khitoh Fatahilah is with Department of Marine Engineering, Institut Teknologi Sepuluh Nopember, Surabaya, 60111, Indonesia. Email: kitofatahilah15@gmail.com higher than when kept in an uncontrolled atmosphere.

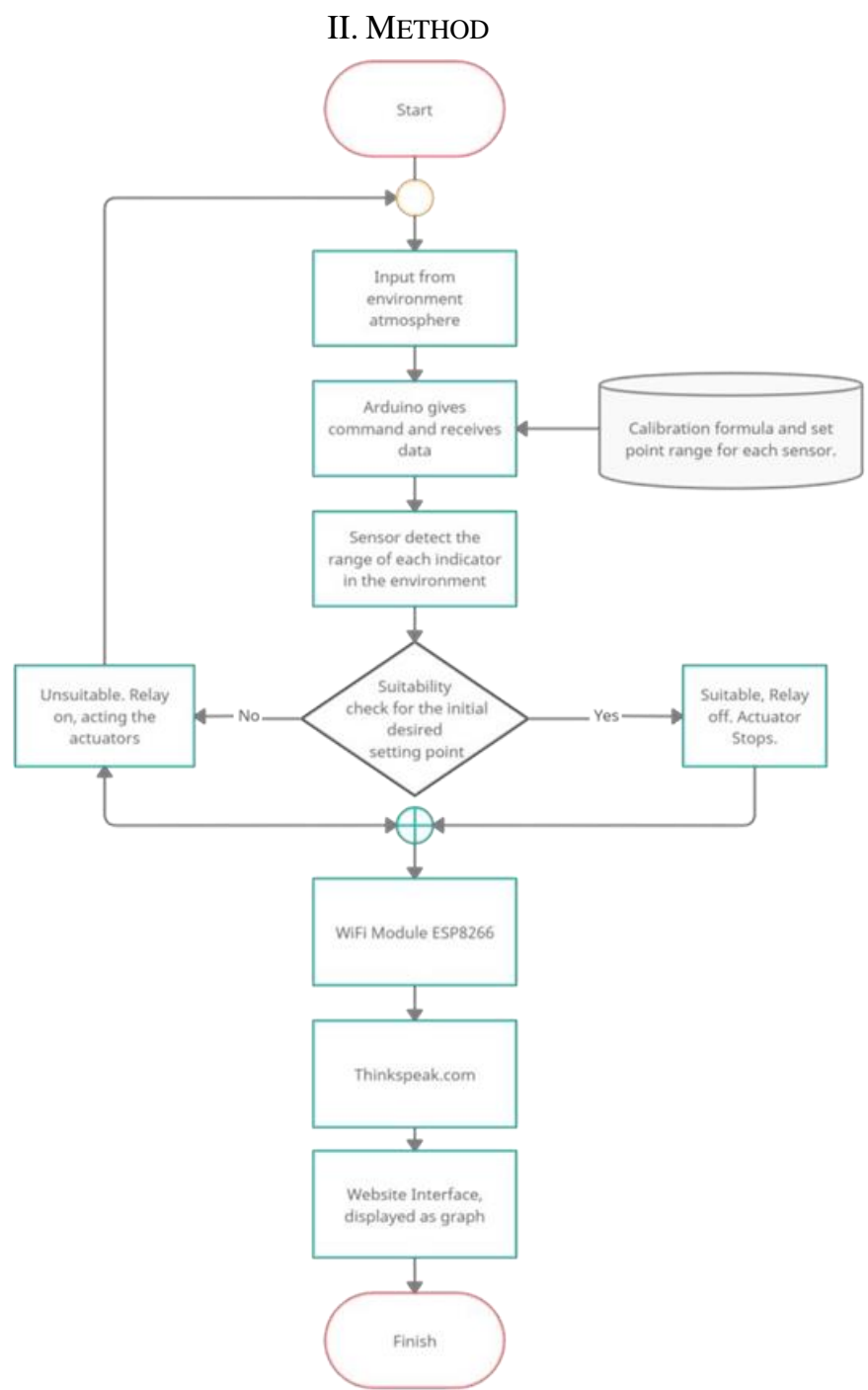

Figure. 1. Flow Chart of Controlled Atmosphere Storage Work. 
A. System Design

the design for the equipment is being made.

After collecting references and studying the literature

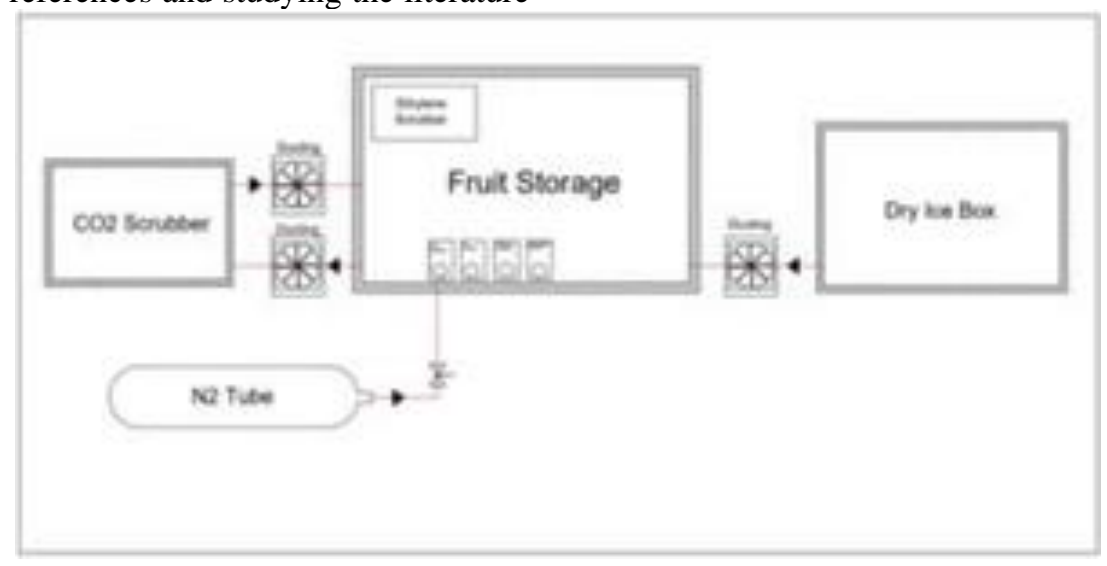

Figure. 2. Schematic Design of CAS system.

It includes mechanical and electrical systems. The mechanical parts will consist of the storage, fluid transfer system, scrubber, and ducting. While the electrical part will consisting of the microcontroller and sensors.

The CAS system design consists of one cargo compartment, one cooling compartment, and a compartment for the scrubber. Following its function, cooling air will be flowed into the cargo compartment using a fan and its capacity will be controlled using a ducting clap. Meanwhile, the levels of various elements such as oxygen and carbon dioxide will be manipulated by a valve connected to a tube containing nitrogen and a ducting fan connected directly to the carbon dioxide scrubber compartment. The sensor will be located inside the cargo compartment, while the microcontroller and cable connections are placed on the outside of the compartment and accommodated by an instrument box.

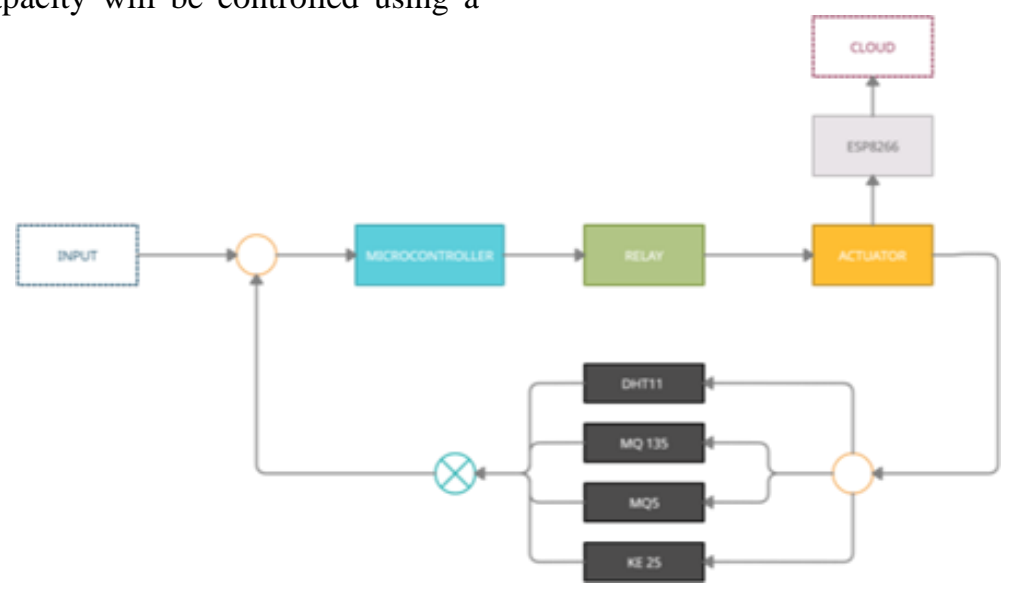

Figure. 3. Block Diagram of Controlled Atmosphere System.

\section{B. Procurement}

Procurement is making a list of available items to be obtained to build the model. The stage will consist of listing affordable equipment and alternative component that might replace the unavailable ones.

\section{Component Assembly}

In this stage, the building and assembly of the component are carried out to make the model. The building will be divided into two sections by mechanical and electrical system build.

\section{Functional Test}

After the model is built. Every component is tested and the sensors are calibrated. This should be done to avoid a huge error margin during data retrieval and further during the data analysis. Also, the range detection of the sensor will be determined here. he Performance of the CAS prototype itself was validated by using data logging to monitor the overall condition of the atmosphere inside the cargo compartment. The software used to do the data logging is PLX-DAQ for Microsoft Excel. The Function Test is performed to simulate a circuit that has been designed. The function test involves all electronic components including fan, sensors, microcontroller, display, relay, adapter, and solenoid valve. From the initial experiment, it was found that the servo was malfunctioning where the input that should move the servo arm by approximately $90^{\circ}$ did not match the resulting output where the servo rotated $360^{\circ}$ many times. It is assumed that the power supply cannot provide sufficient power to serve all components so that another source is needed.

\section{E. Experiment}

In this stage, the experiment is done in certain ways 
to collect data. The experiment that will be done is based on several factors that affect fruit respiration likes temperature, $\mathrm{CO} 2$ and $\mathrm{O} 2$ concentration, and ethylene level.

\section{F. Data Retrieval}

This stage will consist of observation and data collection. The data that will be collected is the amount of time the dry ice took before run out, the change of ethylene level in a certain period, the change in oxygen level, and also the change in carbon dioxide level.

\section{G. Data Analysis}

After the collection is done the analysis will be done on the collected data. The relation between each element will be analyzed and presented in a graphic to give a clear statement of what is effect could each element did on the CAS Storage.

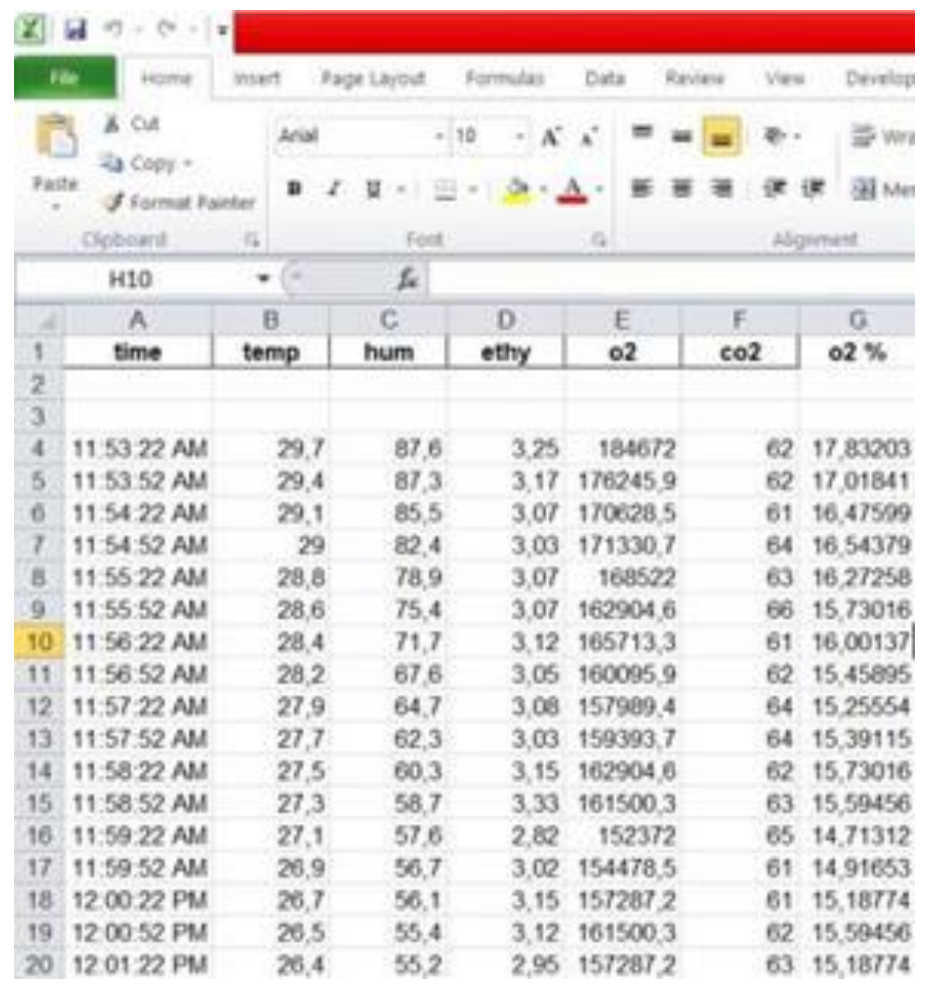

Figure. 3. Data logging using PLX DAQ.

\section{RESULT AND DISCUSSION}

\section{A. KE25 Calibration}

The KE 25 sensor used to detect oxygen must be paired with a Printed Circuit Board to measure oxygen levels. This is because the sensor only produces a voltage of about $15 \mathrm{mV}$ so PCB installation is necessary. The PCB is composed of two resistors valued at $100000 \Omega$ and $1000 \Omega$ also one Integrated Circuit LM385

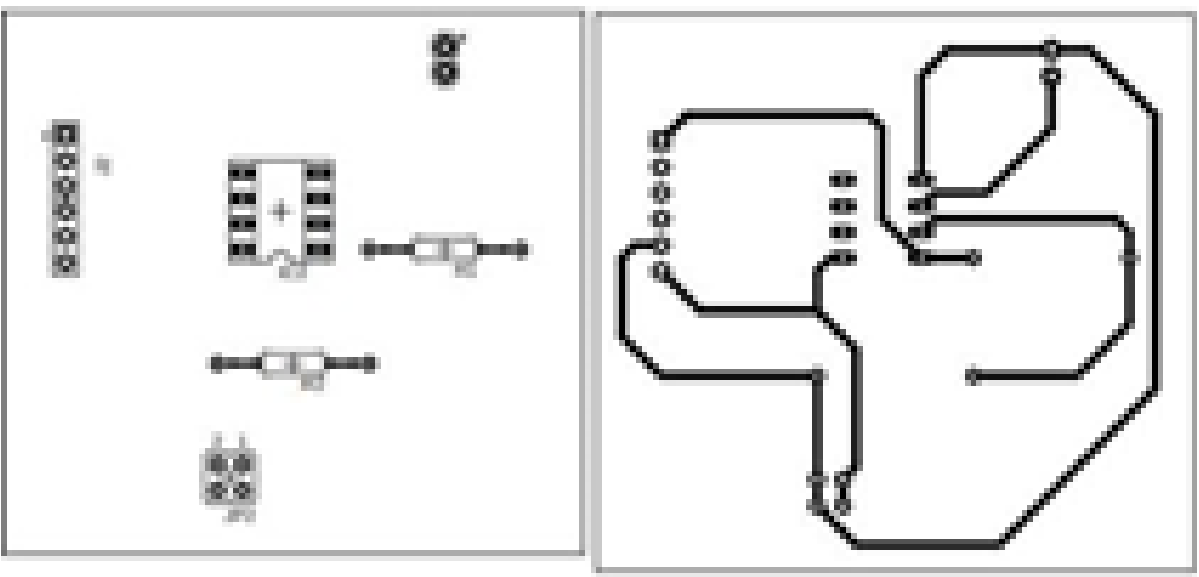

Figure. 4. 5 PCB for KE 25 sensor amplifier. 
TABLE 1.

\begin{tabular}{cccc} 
& ATMOSPHERE COMPOSITION LEVEL TABLE \\
\hline Gas & $\begin{array}{c}\text { \%by } \\
\text { Volume }\end{array}$ & $\begin{array}{c}\text { \%by } \\
\text { Weight }\end{array}$ & $\begin{array}{c}\text { Parts per } \\
\text { Millions }\end{array}$ \\
\hline Nitrogen & 78.08 & 75.47 & 780790 \\
Oxygen & 20.95 & 23.20 & 209445 \\
Argon & 0.93 & 1.28 & 9339 \\
Carbon & 0.040 & 0.062 & 404 \\
Dioxide & & & \\
\hline
\end{tabular}

Furthermore, the oxygen level is detected by analog output from the sensor which can be read on the ADC on the serial monitor.

\section{B. MQ5 Calibration}

MQ5 is a sensor that can be used to measure the level of natural gas. In the case of CAS being used, MQ5 is used to measure the ethylene content produced by the fruit. By knowing the ethylene level we can monitor the ripeness period of the fruit based on the ppm level of the ethylene. A scrubber is also needed to absorb ethylene so that the fruit will last longer before it can fully ripen. To measure ethylene levels, the output voltage from the MQ5 sensor must be calibrated. The way to calibrate is to use a standard level of natural gas in free air.

\section{MQ135 Calibration}

The CO2 detection sensor used is the MQ135 sensor. MQ-135 gas sensor is using $\mathrm{SnO} 2$ which has a higher resistance-free air as gas-detecting material. When the level of certain gasses is increasing and become a pollutant, the resistance of the gas sensor diminishes alongside that.

\section{IoT Integration}

By integrating CAS with IoT we can monitor cargo conditions remotely. One website that provides IoT monitoring services is Thingspeak.com. Whereat first we had to connect to the internet through the ESP8266 module. After that do Thingspeak account registration first to create a channel. By writing the API Key of the channel to the Arduino sketch, we can transfer the data obtained and then display it into a graph-based on several predetermined indicators. The next step is to create a field or space for each indicator which will be represented by an indicator graph against time. Finally, we display our location by filling in the longitude and latitude coordinates according to our position.

\section{CONCLUSION}

To be able to receive and send commands independently, a system must have a control system that consists of a microcontroller, sensors, and actuators. In CAS itself, it is necessary to have a control system considering that the projection of CAS is to minimize human interference in air regulation so that time is used optimally to prevent the fruit from ripening quickly. The CAS that has been designed requires four types of sensors for five different indicators to be detected in the CAS cargo compartment. Meanwhile, the actuator from CAS itself utilizes a relay connected to the fan and also the servo to be able to change the airflow capacity. Then to be able to carry out monitoring from a very long distance requires the integration of the Internet of Things on the CAS itself. The microcontroller used is the Arduino Uno, so the software for making sketches is also the Arduino IDE software. The sketch is made to be an input command on a microcontroller. After the command can be properly actualized by the actuator, data retrieval can be started to validate that the CAS that has been built can work properly according to the initial design concept.

A) To design a control system at CAS, three main components are needed, namely a microcontroller, sensors, and actuators. Where the microcontroller works as a device that receives messages from sensors and gives commands to actuators.

B) In monitoring the air in the CAS cargo compartment, KE 25 sensors are needed to monitor oxygen levels, MQ 135 to monitor CO2 levels, DHT 22 to monitor temperature and humidity and MQ5 to monitor ethylene.

C) CAS integration with IoT using the ESP 8266 wifi module which will be connected to the Thinkspeak.com website to finally be able to display the air condition in the CAS in real-time

\section{ACKNOWLEDGMENTS}

We thank our colleagues from the Marine Fluid Machinery and System laboratory in the Marine Engineering Department for sharing their knowledge based on the course of this research, and for their socalled insights.

\section{REFERENCES}

[1] Argo, Bambang Dwi. "Monitoring Gas Oksigen dan Karbondioksida pada Ruang Penyimpanan Sistem Udara Terkontrol.” in Jurnal Rekayasa Mesin 1, no. 3 (2010).

[2] Aziz, Rofan. "Sistem Kontrol Suhu Penyimpan Buah- Sayur pada Mesin Pendingin.” In Jurnal Teknologi Terapan, 2017: 34-36.

[3] Patel, Keyur K. "Internet of Things-IOT: Definition, Characteristics, Architecture, Enabling Technologies, Application \& Future Challenges." in International Journal of Engineering Science and Computing, 2016.

[4] Paul, Souvik. "Microcontroller Based LPG Safety System." In International Journal of Computer Architecture and Mobility 4, no. 3 (2016). 
International Journal of Marine Engineering Innovation and Research, Vol. 6(2), June. 2021. 135-139 (pISSN: 2541-5972, eISSN: 2548-1479)

[5] Sorongan, Erick. "ThingSpeak sebagai Sistem Monitoring Tangki SPBU Berbasis Internet of Things." (JTERA - Jurnal Teknologi Rekayasa) 3, no. 2 (2018).

[6] Suro, Abdul Rauf. "Perancangan Portable Coolbox Berbasis IOT Menggunakan Sistem Kompresi Uap DC.” Final Project, 2020: 40-79.

[7] Widyaningrum, W., Purwanto, Y.A. and Mardjan , S... "Desain Sistem Kontrol dan Monitoring Kondisi Udara pada Controlled Atmosphere Storage Berbasis Mikrokontroler Arduino Uno." Jurnal Keteknikan Pertanian, 6(1), , 2018: pp.75-82.

[8] Ferrer, Gerard et al, "Review on the Methodology used in Thermal Stability Characterization of Phase Change Materials" in Renewable and Sustainable Energy Reviews Vol. 50 (p. $665-$ 685), 2015.

[9] Rao, C.G. "Engineering for storage of fruits and vegetables: cold storage, controlled atmosphere storage, modified atmosphere storage". Academic Press, 2015. 